\title{
Um estudo do impacto do Acordo Comercial com a União Europeia no mercado de café beneficiado
}

\author{
A study of the impact of the Trade Agreement with the European \\ Union on the processed coffee market
}

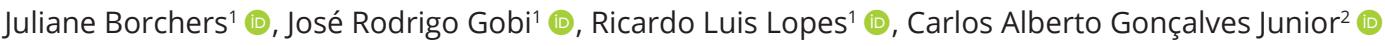

\author{
1Programa de Pós-graduação em Ciências Econômicas, Universidade Estadual de Maringá (UEM), Maringá (PR), Brasil. \\ E-mails: juli_borchers@hotmail.com; joserodrigogobi@gmail.com; rllopes@uem.br \\ ²Departamento de Ciências Econômicas, Universidade Estadual do Oeste do Paraná (Unioeste), Toledo (PR), Brasil. E-mail: carlos.
} junior9@unioeste.br

\begin{abstract}
Como citar: Borchers, J., Gobi, J. R., Lopes, R. L., \& Gonçalves, C. A. (2022). Um estudo do impacto do Acordo Comercial com a União Europeia no mercado de café beneficiado. Revista de Economia e Sociologia Rural, 60(4), e246787. https:// doi.org/10.1590/1806-9479.2021.246787
\end{abstract}

Resumo: O presente artigo procurou avaliar os impactos do Acordo Comercial entre União Europeia (UE) e Mercosul na economia brasileira, concentrando-se no setor do café torrado e solúvel (beneficiado) que terão as tarifas de exportação eliminadas em 4 anos após a implantação do acordo. Este consistirá em uma das maiores áreas de livre comércio do mundo e espera-se que a eliminação das tarifas aumente em 33\% a exportação do setor de café beneficiado para a UE. Empregou-se a análise de Insumo-Produto, a partir de dados das contas nacionais com 128 produtos e 68 setores de 2017, para estimar os índices de ligação de Rasmussen-Hirschman, índices de dispersão e os multiplicadores do produto, renda, impostos e emprego. Observou-se que o aumento nas exportações proporcionará aumento no valor bruto da produção nacional de $R \$ 158,3$ milhões (direta e indiretamente), além de gerar 1,2 mil novos empregos, $R \$ 24,6$ milhões em renda do trabalho e $\mathrm{R} \$ 6,5$ milhões em impostos. Mesmo não sendo um setor-chave na economia brasileira, verificou-se que o crescimento das exportações de café beneficiado, após o acordo, favorecerá a atividade econômica no país, proporcionando crescimento da produção nacional, emprego, renda e impostos.

Palavras-chave: acordo comercial, café solúvel, União Europeia, matriz insumo-produto.

\begin{abstract}
The present article evaluated the impacts of the Trade Agreement between the European Union (EU) and Mercosur on the Brazilian economy, focusing on the sector of roasted and soluble coffee (processed), which will have export tariffs eliminated in 4 years after its implementation. This may be considered one of the largest free trade areas in the world, and the elimination of tariffs is expected to increase exports of the processed coffee sector to the EU by 33\%. Input-Product analysis was used, based on data from the national accounts with 128 products and 68 sectors in 2017, to estimate the Rasmussen-Hirschman connection indexes, dispersion indexes, product, income, taxes, and job multipliers. It was observed that the increase in exports may provide an increase in the gross value of national production of $\mathrm{R} \$ 158.3$ million (directly and indirectly), in addition to generating 1.2 thousand new jobs, R $\$ 24.6$ million in labor income, and $\mathrm{R} \$ 6.5$ million in taxes. Even though this agreement is not considered a key sector in the Brazilian economy, it was found that the growth of processed coffee exports, after its implementation, may favor the country's economic activity, providing growth in national production, employment, income, and taxes.
\end{abstract}

Keywords: trade agreement, soluble coffee, European Union, input-output matrix.

\section{INTRODUÇÃO}

No dia 28 de junho de 2019, foi divulgada a conclusão da negociação do acordo entre o Mercado Comum do Sul (Mercosul) e a União Europeia (UE), após um longo processo começado há vinte anos. $\mathrm{O}$ acordo propriamente dito ainda precisa ser redigido e submetido à aprovação para, finalmente, entrar em vigor. Primeiramente, o acordo comercial anunciado é parte de um Acordo de Associação, que ainda incluirá um pilar político e um de cooperação, já apresentados em 2018. O acordo ainda precisa ser revisto e traduzido em todos os idiomas das partes. 
Em seguida, deve ser assinado pelos países do Mercosul e pela Comissão Europeia, para então ser encaminhado aos Parlamentos do Mercosul e Europeu para aprovação (Nonnenberg \& Ribeiro, 2019).

Segundo Nonnenberg \& Ribeiro (2019), o acordo comercial será bastante extenso e incluirá, entre seus capítulos, os seguintes pontos: comércio de bens; regras de origem; aduanas e facilitação de comércio; defesas e salvaguardas; medidas sanitárias e fitossanitárias; diálogos; barreiras técnicas ao comércio; serviços; compras governamentais; defesa da concorrência; subsídios; empresas estatais; direitos de propriedade intelectual, inclusive denominações de origem; comércio e desenvolvimento sustentável; transparência; integração regional; anexo de vinhos e destilados; temas institucionais, legais e horizontais; pequenas e médias empresas; e solução de controvérsias.

Este artigo se concentra no impacto para a economia brasileira decorrente da conclusão do Acordo Comercial entre União Europeia e Mercosul, com ênfase no setor de café beneficiado, na qual espera-se aumento de $33 \%$ nas exportações segundo o diretor da Associação Brasileira da Indústria de Café Solúvel (ABICS), Aguinaldo José de Lima. É importante destacar que esta pesquisa supõe que o crescimento das exportações ocorrerá por meio da expansão da produção de café torrado e solúvel, sem que haja redução na disponibilidade interna ou redução nas exportações de café em grão. Segundo Nasser et al. (2012), a produção de café passa a ser significativa após três anos e a maior produtividade ocorre em anos pares, portanto sendo possível a ampliação da produção de café ao longo dos 4 anos de eliminação das tarifas.

Nesse cenário, o objetivo do presente artigo é analisar quais serão as vantagens do acordo comercial para a economia brasileira, por meio da análise de quais setores econômicos serão afetados e da magnitude do impacto na produção, renda do trabalho, impostos e geração de renda, considerando o aumento das exportações de café solúvel e torrado. Para isso, utiliza-se a análise da matriz insumo-produto desenvolvida por Leontief.

O setor de café será estudado, pois atualmente é o segundo produto agrícola mais exportado para a União Europeia, representando $18,73 \%$ do total de produtos exportados ligados à agricultura, conforme International Trade Centre (2017). A principal contribuição do estudo é investigar as vantagens do acordo comercial para a economia brasileira, sendo que até o presente momento não foram identificados trabalhos que tratassem o efeito do acordo comercial entre a União Europeia e o Mercosul nas exportações cafeeiras do Brasil.

O artigo está organizado em mais quatro seções, além da introdução e da conclusão. A seção 2 aborda o histórico de negociações do acordo comercial entre o Mercosul e a União Europeia, além de analisar o fluxo comercial entre os dois blocos econômicos. A seção 3 trata da metodologia abordada para estudar o impacto do acordo comercial no setor de café beneficiado. A seção 4 traz os resultados do acordo comercial para o setor de café na geração do produto, renda, emprego e impostos na economia brasileira.

\section{FUNDAMENTAÇÃO TEÓRICA}

\subsection{HISTÓRICO DO ACORDO ENTRE UNIÃO EUROPEIA E MERCOSUL}

O acordo comercial entre Mercosul e União Europeia (UE) é um velho desejo de segmentos empresariais brasileiros. Contudo, entre a visão dos produtos brasileiros ocupando o mercado europeu e ocasionando superávits comerciais e a realidade de um comércio bilateral existe grande distância (Pennaforte et al., 2018). 
Na onda do regionalismo aberto dos anos 1990, a UE constatou a importância de se aproximar da América Latina frente à nova realidade que começava a existir no Cone Sul a partir do fim da Guerra Fria e da ampliação da globalização neoliberal sob o comando dos Estados Unidos (EUA). A assinatura do Tratado de Livre Comércio da América do Norte (NAFTA, em inglês) pelos EUA, Canadá e México, em 1994, foi a indicação de que o novo regionalismo aumentaria nas Américas (Pennaforte et al., 2018).

Alguns anos após o Tratado de Assunção (1991) ser acordado, a União Europeia expôs interesse na aproximação político-econômica com o Mercosul, o que se consolidou em 1995 no Acordo-Quadro de Cooperação entre a União Europeia e o Mercosul. Este acordo entrou em vigor no ano de 1999 e pretendia fomentar iniciativas e condições que permitissem uma associação inter-regional no futuro e sucedeu o início da negociação do acordo de um Tratado de Livre Comércio (TLC) entre os blocos. Contudo, as primeiras propostas efetivas foram expostas apenas em 2004 (Pennaforte et al., 2018).

Os dois blocos tinham expectativas diferentes quanto aos resultados do acordo. Por parte do Mercosul e do Brasil, ansiava-se que o acordo trouxesse maior consolidação de sua imagem na comunidade internacional em sua fase inicial (Bresser-Pereira \& Thorstensen, 1992), como grupo capaz e atuante em promover o apoio do Cone Sul às atividades do bloco e expandir a exportação de seus produtos, notadamente os agrícolas. Já para a União Europeia, a finalidade era de realizar processo gradual de liberalização econômica e inserção em mercados ainda pouco explorados. Todavia, as propostas iniciais não atenderam às expectativas de ambos os lados (Pennaforte et al., 2018).

A falta de coesão interna do Mercosul (principalmente entre Brasil e Argentina) dificultou, ao longo do tempo, a consonância de interesses e de uma proposta comum. Vários fatores podem ser apontados: (i) a possível perda de competitividade argentina na primeira década dos anos 2000, (ii) a crise econômica argentina e (iii) as divergências entre os dois países no ritmo de aprofundamento da integração e da agenda regional (Bernal-Meza, 2005).

Esses fatores colaboraram para a lentidão e a posterior paralisação das negociações. Contudo, existia a concordância na necessidade de se desenvolver mecanismos mais equilibrados para a interação comercial entre os dois blocos desde 2004, apesar da suspensão das negociações em 2007 (Pennaforte et al., 2018).

Em 2010, em consequência da estratégia dos países desenvolvidos de superar a crise por meio da liberalização de novos mercados para seus produtos (Guimarães, 2014), seguido dos efeitos da crise mundial, que passou a afetar também os países em desenvolvimento como o Brasil e Argentina, se gerou nova consonância de interesses entre o Mercosul e a União Europeia (Pennaforte et al., 2018).

\subsection{ANÁLISE DOS FLUXOS BILATERAIS DE COMÉRCIO}

O PIB do Mercosul e da UE somam cerca de US\$20 trilhões, aproximadamente $25 \%$ da economia mundial, englobando grande mercado consumidor de aproximadamente 780 milhões de pessoas. É importante destacar que historicamente a UE é o segundo principal parceiro comercial do bloco sul-americano e o maior investidor. Em 2017, o bloco europeu investiu mais de US\$ 430 bilhões nos países do Mercosul (Brasil, 2020).

O acordo comercial entre os blocos, que em 2017 somaram mais de US\$ 90 bilhões em suas relações comerciais, tem potencial de constituir uma das maiores áreas de livre comércio do mundo. Somente em 2017, o Mercosul exportou mais de US\$ 45,6 bilhões para a UE, aproximadamente $18 \%$ do total exportado pelo bloco (Figura 1). 


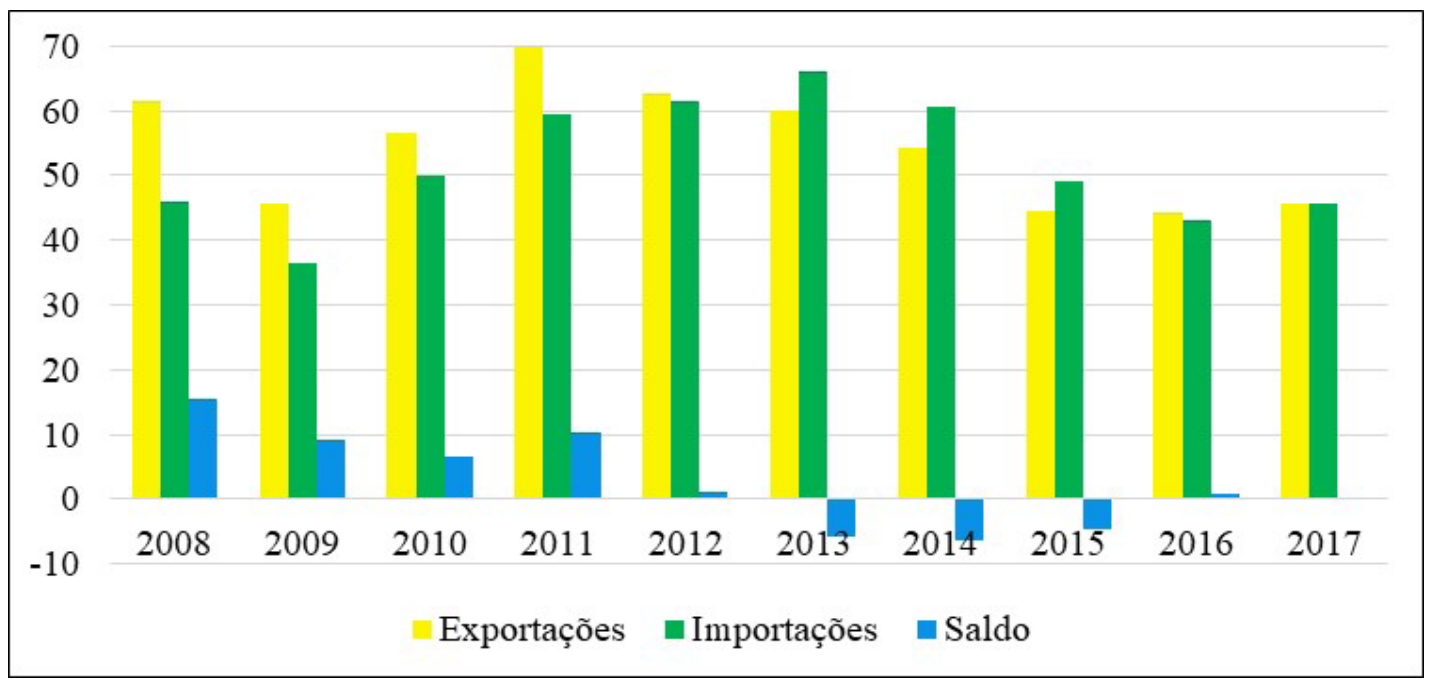

Figura 1 - Comércio Mercosul x União Europeia, 2008 a 2017, bilhões de US\$. Fonte: Elaboração própria a partir de Mercosul (2020).

De maneira específica para o Brasil, a União Europeia foi o segundo principal parceiro comercial em 2017, com corrente de comércio superior a US\$ 61 bilhões (Figura 2). O acordo trará benefícios para diversos setores da economia, tanto para exportadores brasileiros de bens primários quanto para importadores brasileiros de produtos manufaturados da UE (Nonnenberg \& Ribeiro, 2019).

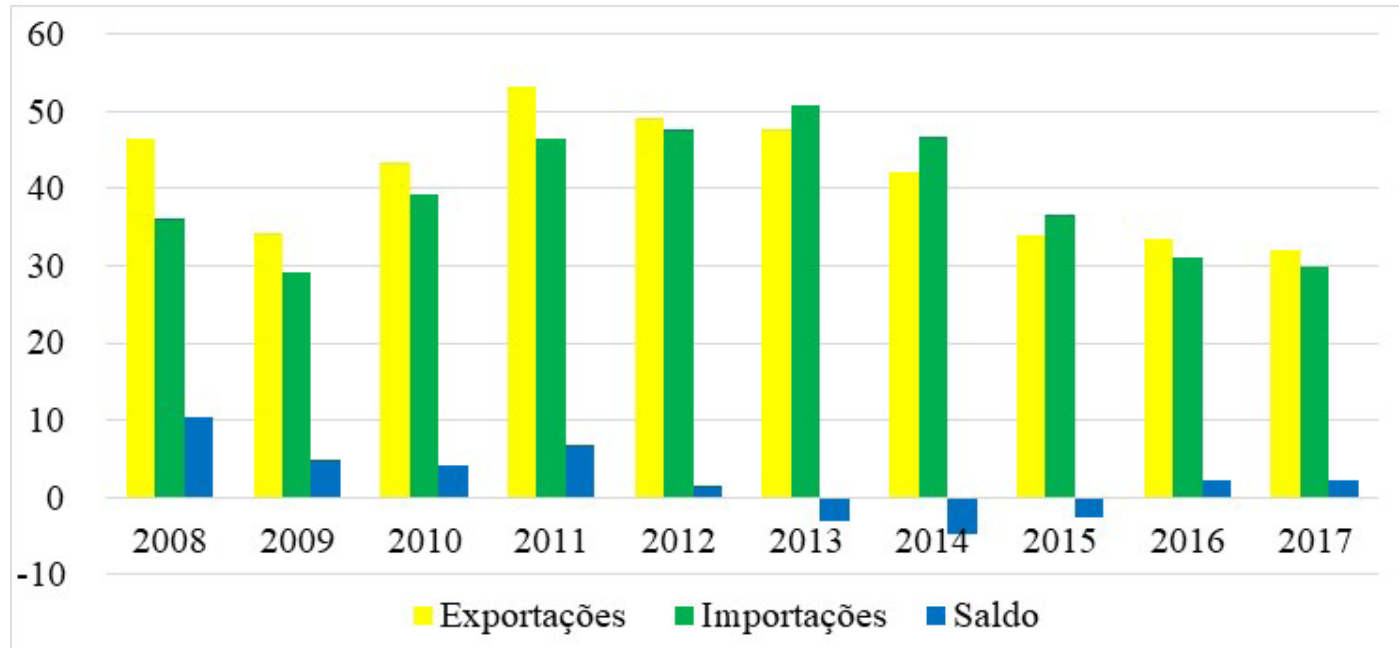

Figura 2 - Comércio Brasil x União Europeia, 2008 a 2017, bilhões de US\$. Fonte: Elaboração própria a partir de Brasil (2020).

Em 2017, as exportações do Brasil para a União Europeia alcançaram mais de US $\$ 32$ bilhões, aproximadamente $15 \%$ da pauta exportadora do país. Entre os principais produtos vendidos, verifica-se forte concentração de minérios, produtos agrícolas, combustíveis e produtos semimanufaturados, atingindo $54,54 \%$ do total exportado para o bloco europeu (Tabela 1). 
Tabela 1 - Exportações do Brasil para a União Europeia segundo produtos em 2017.

\begin{tabular}{|c|c|c|}
\hline Produtos & $\begin{array}{c}\text { Valor (em US\$ } \\
\text { mil) }\end{array}$ & (\%) \\
\hline Farelo e resíduos da extração de óleo de soja & $2.683 .321,81$ & $8,37 \%$ \\
\hline Minério de ferro e seus concentrados & $2.680 .496,37$ & $8,36 \%$ \\
\hline Café não torrado & $2.329 .984,78$ & $7,27 \%$ \\
\hline Celulose & $1.888 .045,94$ & $5,89 \%$ \\
\hline Soja & $1.699 .457,09$ & $5,30 \%$ \\
\hline Óleos brutos de petróleo & $1.453 .879,87$ & $4,54 \%$ \\
\hline Sucos de frutas ou de vegetais & $1.283 .281,34$ & $4,00 \%$ \\
\hline Minérios de cobre e seus concentrados & $1.275 .429,60$ & $3,98 \%$ \\
\hline Obras de ferro ou aço e outros artigos de metais comuns & $1.206 .095,26$ & $3,76 \%$ \\
\hline Ferroligas & $983.162,17$ & $3,07 \%$ \\
\hline Subtotal & $17.483 .154,24$ & $54,54 \%$ \\
\hline Demais Produtos & $14.572 .852,52$ & $45,46 \%$ \\
\hline Total & $32.056 .006,75$ & $100 \%$ \\
\hline
\end{tabular}

Fonte: Elaboração própria a partir de Brasil (2020).

Com relação às importações brasileiras provenientes da UE, observa-se cenário bastante distinto. Foram importados mais de 29,7 bilhões em 2017, mas apenas US\$291,9 milhões referem-se a produtos da agropecuária. Os principais produtos comprados são farmacêuticos, combustíveis, material de transporte, químicos, máquinas e equipamentos, fertilizantes e eletrônicos, alcançando 40,86\% da pauta importadora (Tabela 2).

Tabela 2 - Importações do Brasil oriundas da União Europeia segundo produtos em 2017.

\begin{tabular}{lcc}
\multicolumn{1}{c}{ Produtos } & $\begin{array}{c}\text { Valor } \\
\text { (em mil US\$) }\end{array}$ & (\%) \\
Medicamentos para medicina humana e veterinária & $3.469 .839,86$ & $11,66 \%$ \\
Óleos combustíveis de petróleo (exceto óleos brutos) & $2.095 .558,81$ & $\mathbf{7 , 0 4 \%}$ \\
Partes e acessórios dos veículos automotivos & $1.539 .658,35$ & $5,17 \%$ \\
Compostos heterocíclicos, seus sais e sulfonamidas & $1.108 .702,33$ & $3,72 \%$ \\
Instrumentos e aparelhos de medição, verificação, análise e controle & $731.863,29$ & $2,46 \%$ \\
Outras máquinas e equipamentos especializados para determinadas & $711.683,28$ & $2,39 \%$ \\
indústrias e suas partes & & \\
Adubos ou fertilizantes químicos (exc. fertilizantes brutos) & $650.321,03$ & $2,18 \%$ \\
Motores de pistão, e suas partes & $621.301,91$ & $2,09 \%$ \\
Inseticidas, fungicidas, herbicidas e produtos semelhantes & $618.524,83$ & $\mathbf{2 , 0 8 \%}$ \\
Aparelhos elétricos para ligação, proteção ou conexão de circuitos & $616.135,26$ & $\mathbf{2 , 0 7 \%}$ \\
Subtotal & $\mathbf{1 2 . 1 6 3 . 5 8 8 , 9 4}$ & $\mathbf{4 0 , 8 6 \%}$ \\
Demais Produtos & $17.605 .898,92$ & $\mathbf{5 9 , 1 4 \%}$ \\
Total & $\mathbf{2 9 . 7 6 9 . 4 8 7 , 8 7}$ & $\mathbf{1 0 0 \%}$ \\
\hline
\end{tabular}

Fonte: Elaboração própria a partir de Brasil (2020).

A União Europeia é um grande importador agrícola mundial. O Brasil é hoje o segundo maior fornecedor de produtos agrícolas ao mercado europeu. Em 2017, foram exportados cerca de US $\$ 13,5$ bilhões de produtos agrícolas (16,53\% da pauta exportadora agrícola brasileira), com destaque para o complexo de soja (US $\$ 4,6$ bilhões), café (US $\$ 2,5$ bilhões), carnes (US $\$ 1,6$ bilhões), sucos (US\$1,3 bilhões) e fumo e seus produtos (US\$ 801 milhões), conforme Figura 3. Para os quatro primeiros produtos, o Brasil já se destaca entre os cinco maiores fornecedores da UE, mesmo considerando os fornecedores europeus intrazona (Brasil, 2020). 


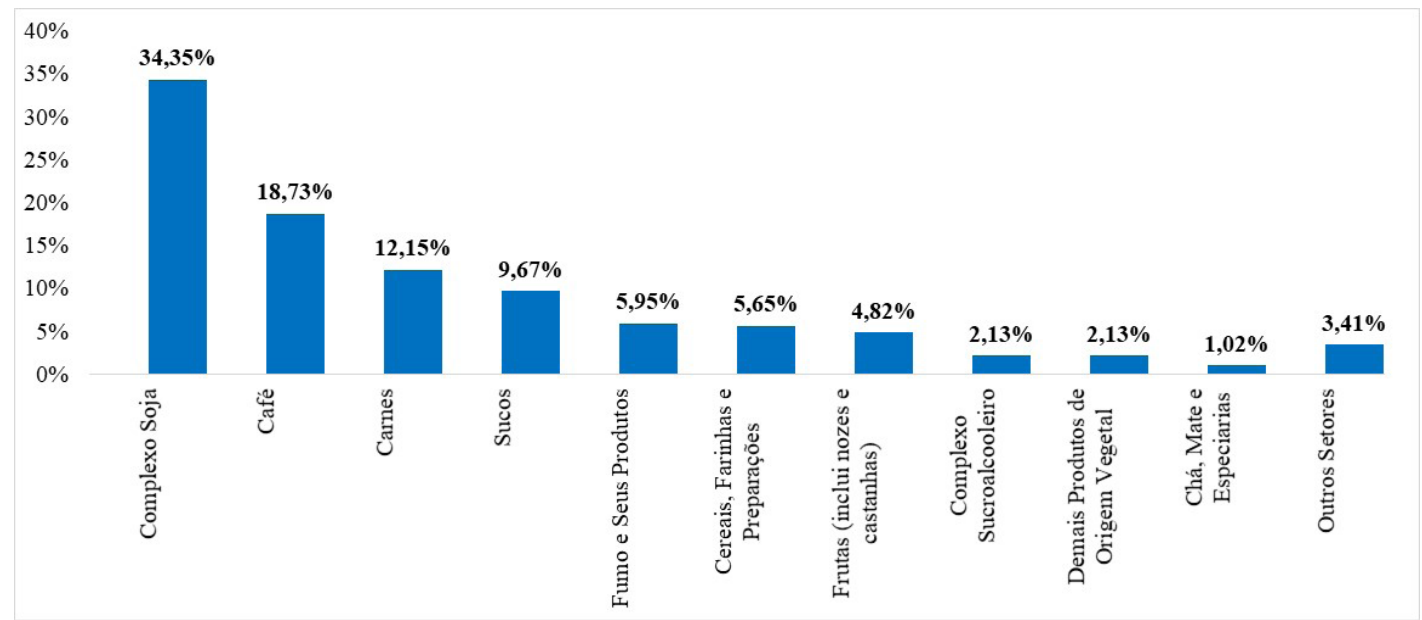

Figura 3 - Exportações - Setores Agrícolas - Brasil - União Europeia - 2017. Fonte: Elaboração própria a partir de International Trade Centre (2017).

Em relação ao café, o Brasil exportou US\$2,5 bilhões para a UE, correspondendo a 18,73\% dos produtos agrícolas exportados para o bloco. A exportação de café é classificada em quatro produtos: (1) café cru em grão; (2) café solúvel; (3) café torrado, descafeinado ou não; e (4) extratos, essências, concentrado de café, exceto café solúvel. O principal produto exportado é o café cru em grão $(96,2 \%)$, pois atualmente não há tarifas de exportação para esse produto. Em seguida, tem-se o café solúvel (3,75\%), café torrado (0,03\%), extratos, essências, concentrado de café, exceto café solúvel (0,02\%). Os produtos afetados pelo acordo comercial serão o café solúvel e o café torrado. Está previsto que essas tarifas de exportação serão eliminadas em 4 anos após a implantação do acordo.

\section{METODOLOGIA}

Nesta seção, estão apresentadas a fonte e descrição dos dados, bem como os métodos empíricos usados no presente estudo.

\subsection{MATRIZ DE LEONTIEF}

O modelo de insumo-produto possui o objetivo de descrever as interações entre os setores de uma economia com base nas relações de entrada e saída. Esse sistema de interdependência é mostrado na tabela de insumo-produto, que preserva as identidades macroeconômicas. Essa estrutura se constitui em um sistema de equações lineares em que cada uma representa a distribuição da produção de um setor entre os demais, sobre a forma de insumos, e a demanda final, constituída pelo consumo das famílias, governo, formação de capital e exportações (Guilhoto, 2011; Miller \& Blair, 2009; Zheng et al., 2020).

Por meio da matriz insumo-produto, foi utilizado o modelo puro de Leontief indicando que fluxos de bens e serviços produzidos em cada setor da economia, designados a servir de insumos a outros setores e também atender à demanda, podem ser representados por meio de equações simultâneas (Miller \& Blair, 2009; Takasago et al., 2017).

A equação proposta por Leontief (1951) pode ser expressa da seguinte forma: 
Onde x representa um vetor $(n x 1)$ com o valor da produção setorial; A é uma matriz $(n x n)$ com os coeficientes técnicos de produção e $Y$ é um vetor $(n x 1)$ com os valores da demanda final setorial. No modelo demonstrado, o vetor da demanda final é tratado como a variável exógena ao sistema. Dessa forma, o vetor x é estabelecido unicamente pelo vetor Y (Miller \& Blair, 2009; Chen et al., 2018):

$X=B Y$

$B=(I-A)^{-1}$

Onde a Equação 3 representa a matriz $\left({ }^{n x n}\right)$, que abrange a matriz $(I-A)^{-1}$, a conhecida matriz de Leontief que mostra os coeficientes diretos e indiretos da demanda final (Shao et al., 2017). Desse modo, as Equações 1, 2 e 3 são equações que, em conjunto com outras, servem de intermédio para a análise da realidade. Assim, o modelo básico de Leontief fornece a seguinte equação (Chen et al., 2018; Takasago et al., 2017):

$X=(I-A)^{-1} \Delta Y$

\section{2 ÍNDICES DE LIGAÇÃO DE HIRSCHMAN-RASMUSSEN}

Os índices de ligação de Hirschman-Rasmussen mostram a força de encadeamento de um setor. Os índices possuem duas abordagens, o índice de encadeamento para trás ou para montante apresenta a força que um setor tem de demandar produtos e serviços de outros setores. Em segundo, o índice de encadeamento para frente ou a jusante mostra a força com que um setor é puxado através da oferta de produtos utilizados como insumo por outros setores (Takasago et al., 2017).

Antes de propriamente apresentar a forma funcional dos índices, deve-se primeiro demonstrar algumas relações.

$L_{* j}=\sum_{i=1}^{n} L_{i j}, j=1, \ldots, n$

$L_{i *}=\sum_{j=1}^{n} L_{i j}, i=1, \ldots, n$

$L_{*}=\sum_{i=1}^{n} \sum_{j=1}^{n} L_{i j}$

A Equação 5 se refere à soma nas colunas dos coeficientes técnicos diretos e indiretos para cada setor comprador, seguida pela Equação 6 que descreve a soma nas linhas da matriz L para cada setor vendedor e, por fim, $\mathrm{L}_{*}$ representa a soma de todos os coeficientes técnicos diretos e indiretos da matriz (Miller \& Blair, 2009).

Segundo Guilhoto (2011), o cálculo dos índices de ligação para trás $U_{j}$ e para frente $U i$ seguem a seguinte forma funcional:

$U_{j}=\frac{L_{j^{*}} / n}{L_{*} / n^{2}}, j=1, \ldots, n$ 
$U_{i}=\frac{L_{i} / n}{L_{*} / n^{2}}, i=1, \ldots, n$

Quanto maior for o índice de ligação de um setor, maior será sua força de encadeamento. O índice calcula a média de encadeamento de um setor em razão da média de todos os setores, dessa forma, se $U i, U j>1$ dizemos que o setor é chave, ou seja, o setor encadeia outros setores acima da média (Guilhoto, 2011; Takasago et al., 2017).

\section{3 ÍNDICES DE DISPERSÃO}

Outra maneira de avaliar o encadeamento de um setor é através do índice de dispersão, pois um setor pode ser chave, no entanto encadear poucos setores. Significa dizer que um setor pode apresentar encadeamento alto, no entanto esse encadeamento se deve a poucos setores que o setor puxa ou é puxado. As Equações 10 e 11 representam os desvios padrão das colunas e das linhas, respectivamente (Nassif et al., 2015; Takasago et al., 2017):

$$
\begin{aligned}
& D P\left(L_{*_{j}}\right)=\sqrt{\sum_{i=1}^{n}\left(L_{i j}-L_{*_{j}} / n\right), i=1, \ldots, n} \\
& D P\left(L_{i^{*}}\right)=\sqrt{\sum_{j=1}^{n}\left(L_{i j}-L_{i^{*}} / n\right), i=1, \ldots, n}
\end{aligned}
$$

As formas funcionais dos índices de dispersão para trás e para frente estão representados, respectivamente, nas Equações 12 e 13 (Takasago et al., 2017):

$$
\begin{aligned}
& V_{j}=\frac{D P\left(L_{k_{j}}\right)}{L_{*_{j}} / n}, j=1, \ldots, n \\
& V_{i}=\frac{D P\left(L_{i^{*}}\right)}{L_{i^{*} /} n}, i=1, \ldots, n
\end{aligned}
$$

Os índices de dispersão para trás são o desvio padrão de cada coluna em razão da respectiva média e o índice de dispersão para frente nas linhas. Se o índice de dispersão for baixo, significa dizer que esse encadeamento é homogêneo entre os setores e se apresenta uma alta dispersão, o encadeamento se restringe a poucos setores (Nassif et al., 2015; Takasago et al., 2017).

\subsection{MULTIPLICADORES}

Os multiplicadores mostram o impacto em uma variável específica de um aumento de uma unidade monetária adicional na demanda final de um setor. Os multiplicadores podem ser analisados em quaisquer variáveis, desde que se tenham dados da variável para cada setor. Neste trabalho, os multiplicadores foram calculados para produção, imposto, emprego e renda do trabalho (Miller \& Blair, 2009).

O cálculo para multiplicador de produção para cada setor segue na Equação 14 (Guilhoto, 2011):

$P_{j}=\sum_{i=1}^{n} L_{i j}, j=1, \ldots, n$ 
Conforme Takasago et al. (2017), para outras variáveis, além dos coeficientes da matriz inversa de Leontief, precisa-se do valor ou quantidade da variável Ypara cada setor j. Posteriormente deve-se calcular o coeficiente yi da variável por unidade monetária do valor da produção como especificado na Equação 15:

$y_{i}=\frac{Y_{j}}{X_{j}}, j=1, \ldots, n e i=j$

deste modo, o multiplicador da variável $M Y$ para cada setor jé:

$M Y_{j}=\frac{\sum_{i=1}^{n} y_{i} L_{i j}}{y_{i}}, j=1, \ldots, n$

Por meio das Equações 15 e 16, pode-se calcular o multiplicador para quaisquer variáveis (Guilhoto, 2011).

\subsection{EVIDÊNCIAS EMPÍRICAS}

A metodologia de insumo-produto tem sido utilizada em inúmeras pesquisas, em virtude da capacidade de apresentar as relações entre os setores da economia ao relacionar os fluxos de bens e serviços e apontar as relações intersetoriais dentro do sistema econômico de determinada região. Na literatura, destacam-se diversas investigações que utilizaram essa abordagem para análises agrícolas e ambientais (Goodlass et al., 2001; Ozkan et al., 2004; Shao et al., 2017; Chen et al., 2018; Zheng et al., 2020).

A análise insumo-produto tem sido constantemente utilizada para estudar o setor de café brasileiro. Sugai et al. (2004) avaliaram o impacto da exportação do café em coco e dos produtos do café na economia do Brasil, especificamente o efeito na indução do produto interno bruto (PIB) e da absorção de mão de obra. A metodologia empregada foi o sistema nacional da matriz insumo-produto para o ano de 1996. Os resultados mostraram que a exportação do café em coco tem menos impacto na indução do PIB do que a exportação dos produtos industrializados do café, indicando que o Brasil deve processar mais café com tecnologia avançada e exportar esses produtos. Por outro lado, a absorção da mão de obra teve maior impacto na exportação do produto do setor primário do que o produto industrializado. Portanto, o setor primário, ao qual pertence o café em coco, absorve mais mão de obra do que os demais setores a que pertencem os produtos do café.

Já o trabalho de Sakon et al. (2008) procurou estudar o setor de produção e processamento do café brasileiro. Os autores examinaram o comportamento e importância dos setores de produção agrícola e da industrialização do café nos principais estados produtores brasileiros (Minas Gerais, Espírito Santo, São Paulo, Paraná, Bahia e Rondônia) e nos demais setores da economia nacional em 2002. Para isso, realizaram simulações em diferentes cenários empregando um sistema inter-regional de insumo-produto. Os cenários estimados revelam a diversidade de impactos sobre a produção, não apenas localmente, mas também globalmente por meio das relações inter-regionais e intersetoriais. Esses resultados indicam a eficiência da modelagem insumo-produto para pesquisas desse tipo.

Outros estudos investigaram apenas um estado produtor em específico. Santos et al. (2009) analisaram o setor de produção e processamento de café no estado de Minas Gerais, procurando determinar sua importância e seus encadeamentos dentro da estrutura do estado. Para isso, utilizaram a matriz regional de Minas Gerais de 1995. Observaram que os setores produtivos do café em coco e da indústria do café contribuem, significativamente, para o crescimento da 
economia mineira e que os incentivos direcionados aos setores cafeeiros, além de elevar os níveis de produto, renda e emprego nos próprios setores geram externalidades positivas nos demais setores da economia estadual.

Seixas et al. (2020) utilizaram a matriz insumo-produto regional de Minas Gerais de 2008 e 2013 com o objetivo de verificar o impacto da crise financeira de 2008 na estrutura cafeeira do estado. Os resultados sugerem que a indústria cafeeira mineira, que já era pouco relevante, tornou-se ainda mais incipiente no período analisado. Perceberam, também, que as ligações entre o café em grão e café industrializado se enfraqueceram nesse período.

A partir desta revisão, foi possível observar a aplicabilidade da técnica de insumo-produto em avaliar adequadamente as relações estruturais entre a produção e processamento do café e determinar a importância do setor e seus encadeamentos dentro da estrutura nacional. Além disso, permite avaliar o impacto de possíveis aumentos da exportação do produto café na economia do país, principal enfoque deste trabalho. É importante destacar que até o presente momento não foram identificadas aplicações que abordassem o efeito do acordo comercial entre a União Europeia e o Mercosul nas exportações cafeeiras do Brasil.

\subsection{BASE DADOS E DESAGREGAÇÃO DO SETOR ESTUDADO}

Este artigo utiliza dados da matriz insumo-produto de 2017 para o Brasil, disponibilizada pelo Núcleo de Economia Regional e Urbana da USP (2021). A matriz foi construída com base no Sistema de Contas Nacionais (SCN), divulgado pelo Instituto Brasileiro de Geografia e Estatística (IBGE) em novembro de 2019 (Instituto Brasileiro de Geografia e Estatística, 2017). O método de estimação adotado consiste na adequação conjunta dos procedimentos descritos em Guilhoto \& Sesso Filho $(2005 ; 2010)$. A matriz de produção diz respeito aos 128 bens produzidos pelos 68 setores. Já a matriz de usos mostra os insumos, em um grau de desagregação de 128 produtos e serviços utilizados na produção desses 68 setores.

\subsubsection{Criação do setor de café beneficiado}

Conforme já apresentado, este artigo procura estudar os impactos do acordo comercial entre Mercosul e União Europeia para a economia brasileira, com foco no setor do café torrado e solúvel. Para atingir esse objetivo, é necessário criar um novo setor na matriz insumo-produto, somente referente ao produto café beneficiado, pois é nele que estão contidas as produções de café solúvel e torrado.

O café beneficiado é um dos 128 bens produzidos que estão demonstrados na matriz insumo-produto do Brasil em 2017. Para analisar os impactos do acordo comercial, criou-se o setor de café beneficiado na matriz de produção. Para isso agregou-se no novo setor toda a produção referente a esse produto que estava englobado nos setores da agricultura, pecuária, produção florestal, fabricação e refino de açúcar, outros produtos alimentares e comércio por atacado e varejo. Assim, nesses setores, a produção de café beneficiado foi zerada e alocada para o setor criado especialmente para a realização do choque.

Para criar o novo setor na matriz de usos, é necessário considerar a fração da produção de café beneficiado em proporção da produção total dos setores da agricultura, pecuária, produção florestal e refino de açúcar, outros produtos alimentares e comércio por atacado e a varejo, apresentadas na matriz de produção. As proporções são exibidas na Tabela 3. 
Tabela 3 - Participação do café beneficiado nos setores em 2017.

\begin{tabular}{lccc} 
Setor & $\begin{array}{c}\text { Produção de } \\
\text { café beneficiado } \\
\text { (milhões) }\end{array}$ & $\begin{array}{c}\text { Total da produção no } \\
\text { setor (milhões) }\end{array}$ & Participação \\
\hline Agricultura & 105 & 356.847 & $0,0294 \%$ \\
Pecuária & 52 & 147.583 & $0,0352 \%$ \\
Produção Florestal & 2 & 36.146 & $0,0055 \%$ \\
Fabricação e refino de açúcar & 15 & 62.659 & $0,0239 \%$ \\
Outros produtos alimentares & 13.263 & 290.387 & $4,5674 \%$ \\
Comércio por atacado e a varejo & 298 & 1.048 .649 & $0,0284 \%$ \\
\hline
\end{tabular}

Fonte: Elaborado a partir dos dados da pesquisa (2020).

\subsubsection{Impactos diretos e indiretos das exportações de café no Brasil}

As informações sobre as exportações de café beneficiado também estão agrupadas em outros setores. Por esse motivo, criou-se o setor de café beneficiado, desagregando esse produto dos outros setores. Para isso, utilizaram-se as matrizes de produção e usos. A partir das novas matrizes, nas quais contém o novo setor, foi calculada uma nova matriz inversa de Leontief.

Após o cálculo da nova matriz inversa de Leontief, cria-se um vetor de impacto da demanda final $\Delta f$. Esse vetor assume valor nulo em todas as linhas, com exceção da linha correspondente ao setor de café beneficiado que assume o valor do choque nas exportações desse produto no Brasil. Deste modo, evidencia-se a demanda final gerada pelo aumento das exportações de café beneficiado no Brasil, devido ao acordo comercial entre Mercosul e União Europeia.

O impacto dos efeitos diretos e indiretos na produção é calculado pela Equação 4. Já para medir os impactos no emprego, impostos e na renda do trabalho, é preciso criar um vetor diagonalizado dos coeficientes yi. Com o vetor diagonalizado e o vetor de produção, volta-se ao vetor da variável $Y$ como expresso na Equação 17 e 18:

$Y=\hat{y} X$

$\Delta Y=\hat{y} \Delta X$

Inserindo a Equação 4 em (18), pode-se calcular o efeito de alterações na demanda final na variável de análise $Y$ em cada setor:

$\Delta Y=\hat{y}(I-A)^{-1} \Delta f$

A partir da Equação 19, foi calculado o valor adicionado gerado direta e indiretamente pelo setor de café beneficiado, além dos empregos, impostos e da renda do trabalho em nível setorial.

\subsubsection{Valor do choque considerado}

Para atingir o objetivo proposto, será considerado aumento de 33\% nas exportações do setor de café beneficiado. Essa taxa foi obtida em entrevista da Revista Exame (2019) com Aguinaldo José de Lima, diretor da Associação Brasileira da Indústria de Café Solúvel (ABICS). 
Conforme o diretor da associação, estima-se que o impacto nas exportações do setor será de $33 \%$ em cinco anos. Para obter esse valor, foi realizada uma média ponderada da projeção de crescimento apresentada por cada uma das cinco maiores associadas da ABICS, que respondem por $100 \%$ das exportações para a União Europeia. Além disso, considerou-se o histórico das exportações do setor observando o período em que estava no Sistema Geral de Preferências (SGP) e quando o deixou (SGP), passando a ser taxado em 9\%. Em 2012, por exemplo, o setor exportava 18.699.923 quilos, porém, em 2019, com a taxação de 9\%, exportou apenas 12.791.423 quilos, redução de $31,6 \%$.

Para definir o valor do choque a ser realizado, considerou-se a participação das exportações de café beneficiado para o bloco europeu em relação ao total exportado desse setor. Em 2017, o Brasil exportou US\$95,9 milhões de café beneficiado para a UE, sendo que o total exportado desse produto para o mundo foi de US\$673,1 milhões. Deste modo, a participação da UE nas exportações de café beneficiado foi de 14,25\%.

Posteriormente, aplicou-se essa participação no valor total das exportações na matriz insumo-produto exibida na matriz de usos. Como o valor total das exportações do setor de café beneficiado foi de $R \$ 1.511,02$ milhões, verifica-se que $R \$ 215,3$ milhões foram exportados para o bloco europeu. Neste valor, foi aplicado o percentual de 33\% referente ao aumento salientado pelo Aguinaldo José de Lima, diretor da ABICS. É importante destacar que, para este caso, espera-se que o aumento nas exportações ocasionará um aumento da produção de café ao longo desses cinco anos, não havendo redução na disponibilidade interna nem diminuição da exportação de café em grãos.

Diante do exposto, o valor do choque a ser realizado foi de $\mathrm{R} \$ 71,06$ milhões ao longo dos cinco anos. O valor do choque é aplicado diretamente em apenas um ano, pois a metodologia de insumo-produto considera retornos constantes à escala, ou seja, não haveria diferenças nos resultados se aplicássemos o impacto ano a ano.

\section{RESULTADOS E DISCUSSÃO}

Os resultados desta pesquisa são apresentados em três partes e apenas para os dez principais setores e o setor de café beneficiado (setor em estudo). Primeiramente, analisam-se os índices de Hirschman-Rasmussen, os quais foram obtidos utilizando-se a matriz de insumo-produto de 2017. Em seguida, discutem-se os multiplicadores de produção, renda, impostos e emprego. Por fim, apresentam-se os impactos na economia brasileira do aumento da exportação de café beneficiado para a União Europeia.

\subsection{OS ÍNDICES HIRSCHMAN-RASMUSSEN}

Nas Tabelas 4, 5, 6 e 7, estão apresentados os índices de ligação e de dispersão para os dez principais setores da economia brasileira e o setor de café beneficiado (setor em estudo) em 2017. Os índices de Hirschman-Rasmussen demonstram a força de encadeamento de um determinado setor e, por isso, são importantes para compreender a interdependência setorial e seu impacto na economia. A análise desse índice auxilia na alocação efetiva dos recursos escassos em setores que mais contribuem para o crescimento da atividade econômica.

Além do índice de ligação, outra forma de avaliar o encadeamento de um setor é por meio do índice de dispersão. Esse índice permite medir se a força de encadeamento se espalha para outros setores ou se concentra em alguns, sendo que, quanto maior o índice, a ligação não é uniforme e significa que a ligação não se espalha para muitos setores. 
Analisando os índices de ligações para trás, verifica-se que o setor de café beneficiado, apresenta índice de ligação para trás superior à unidade (Tabela 4). Esse resultado indica que o setor de café beneficiado é um demandante de insumos acima da média do restante da economia.

Tabela 4 - Índices de Ligação para Trás.

\begin{tabular}{|c|c|c|}
\hline Setor & Valor & Ordem \\
\hline Abate e produtos de carne & 1,3394 & 1 \\
\hline Fabricação de biocombustíveis & 1,2667 & 2 \\
\hline Fabricação de automóveis, caminhões e ônibus, exceto peças & 1,2649 & 3 \\
\hline Fabricação e refino de açúcar & 1,2603 & 4 \\
\hline Outros produtos alimentares & 1,2414 & 5 \\
\hline Refino de petróleo e coquerias & 1,2397 & 6 \\
\hline Café beneficiado & 1,2296 & 7 \\
\hline Produção de ferro-gusa/ferroligas & 1,1988 & 8 \\
\hline Fabricação de bebidas & 1,1893 & 9 \\
\hline Fabricação de produtos de fumo & 1,1830 & 10 \\
\hline
\end{tabular}

Fonte: Elaborado a partir de dados da pesquisa (2020).

No que diz respeito aos índices de ligações para frente, verifica-se que 35 setores vendem seus insumos para os outros setores, acima da média nacional. Com relação ao setor de café beneficiado (Tabela 5), observa-se que apresenta índice de ligação para frente menor que a unidade, indicando que os produtos desse segmento são pouco utilizados por outros setores no processo produtivo, sendo destinados à demanda final, principalmente para consumo das famílias e exportação.

Tabela 5 - Índices de Ligação para Frente.

\begin{tabular}{|c|c|c|}
\hline Setor & Valor & Ordem \\
\hline Atividade de televisão, rádio, cinema e gravação & 1,8912 & 1 \\
\hline Impressão e reprodução de gravações & 1,5672 & 2 \\
\hline Extração de carvão mineral & 1,5179 & 3 \\
\hline Fabricação de químicos & 1,5072 & 4 \\
\hline Outras atividades profissionais, científicas e técnicas & 1,4462 & 5 \\
\hline Atividades jurídicas, contábeis, consultoria & 1,4377 & 6 \\
\hline Fabricação de defensivos, desinfetantes, tintas e químicos diversos & 1,4359 & 7 \\
\hline Manutenção de máquinas e equipamentos & 1,4352 & 8 \\
\hline Atividades de vigilância, segurança e investigação & 1,4187 & 9 \\
\hline Aluguéis não-imobiliários & 1,3851 & 10 \\
\hline Café beneficiado & 0,6629 & 59 \\
\hline
\end{tabular}

Fonte: Elaborado a partir de dados da pesquisa (2020).

No que concerne aos coeficientes de dispersão dos índices de ligação para trás para o setor de café beneficiado (Tabela 6), verifica-se que o coeficiente do índice é menor que a média de todos os setores da economia brasileira, indicando que esse segmento está relativamente bem articulado com os outros setores. Dessa forma, variações na produção do setor de café beneficiado tenderia a estimular os demais de maneira uniforme. 
Tabela 6 - Índices de Dispersão para Trás.

\begin{tabular}{|c|c|c|}
\hline Setor & Valor & Ordem \\
\hline Serviços domésticos & 8,3066 & 1 \\
\hline Atividades imobiliárias & 7,4762 & 2 \\
\hline Educação pública & 6,7925 & 3 \\
\hline Atividades de vigilância, segurança e investigação & 6,7020 & 4 \\
\hline Intermediação financeira & 6,5799 & 5 \\
\hline Produção florestal & 6,4463 & 6 \\
\hline Ativid. jurídicas, contábeis, consultoria & 6,2642 & 7 \\
\hline Desenvolvimento de sistemas & 6,2481 & 8 \\
\hline Energia elétrica, gás natural & 6,1834 & 9 \\
\hline Administração pública, defesa e seguridade social & 6,0479 & 10 \\
\hline Café beneficiado & 3,8623 & 68 \\
\hline
\end{tabular}

Fonte: Elaborado a partir de dados da pesquisa (2020).

Em relação aos coeficientes de dispersão dos índices de ligação para frente (Tabela 7), percebe-se que o setor de café beneficiado apresenta valor maior que o da média de setores da economia, significando que a demanda por este setor ocorre de maneira relativamente concentrada. Esse resultado está relacionado com a demanda final, como já destacado anteriormente.

Tabela 7 - Índices de Dispersão para Frente.

\begin{tabular}{|c|c|c|}
\hline Setor & Valor & Ordem \\
\hline Serviços domésticos & 8,3066 & 1 \\
\hline Saúde pública & 8,2855 & 2 \\
\hline Saúde privada & 8,2852 & 3 \\
\hline Fabricação de produtos de fumo & 8,2639 & 4 \\
\hline Educação pública & 8,2352 & 5 \\
\hline Fabricação de calçados e couro & 8,0467 & 6 \\
\hline Fabricação de automóveis, caminhões e ônibus, exceto peças & 8,0342 & 7 \\
\hline Administração pública, defesa e seguridade social & 7,9129 & 8 \\
\hline Confecção de vestuário e acessórios & 7,4952 & 9 \\
\hline Construção & 7,3308 & 10 \\
\hline Café beneficiado & 6,8044 & 14 \\
\hline
\end{tabular}

Fonte: Elaborado a partir de dados da pesquisa (2020).

\subsection{MULTIPLICADORES DE PRODUÇÃO, EMPREGO, RENDA E IMPOSTOS}

Os multiplicadores de insumo-produto podem ajudar no processo de tomada de decisão de políticas públicas que visam o desenvolvimento regional. Isso ocorre, pois eles demonstram o impacto direto e indireto em variáveis selecionadas de uma unidade monetária adicional na demanda final de um determinado setor, ou seja, a força que esse setor tem na geração de produção, empregos, renda do trabalho e impostos. Esses multiplicadores são apresentados nas Tabelas 8, 9, 10 e 11.

O multiplicador de produção mede a relação entre a demanda final e o produto total (Tabela 8). O setor de café beneficiado apresentou o sétimo maior poder de geração de produção em 2017, o que significa que, se a demanda final por produtos desse setor aumentar em mil reais, 
ocorrerá uma variação da produção em todos os setores da economia nacional para atender a essa mudança equivalente a $\mathrm{R} \$ 2.227,20$ (multiplicador de produção do setor), dos quais, mil reais vão para atendimento da demanda final e os $R \$ 1.227,20$ restantes representam a produção gerada nos demais setores da economia.

Tabela 8 - Multiplicador de Produção.

\begin{tabular}{|c|c|c|}
\hline Setor & Valor & Ordem \\
\hline Abate e produtos de carne & 2,4261 & 1 \\
\hline Fabricação de biocombustíveis & 2,2945 & 2 \\
\hline Fabricação de automóveis, caminhões e ônibus, exceto peças & 2,2912 & 3 \\
\hline Fabricação e refino de açúcar & 2,2829 & 4 \\
\hline Outros produtos alimentares & 2,2486 & 5 \\
\hline Refino de petróleo e coquerias & 2,2456 & 6 \\
\hline Café beneficiado & 2,2272 & 7 \\
\hline Produção de ferro-gusa/ferroligas & 2,1715 & 8 \\
\hline Fabricação de bebidas & 2,1543 & 9 \\
\hline Fabricação de produtos de fumo & 2,1428 & 10 \\
\hline
\end{tabular}

Fonte: Elaborado a partir de dados da pesquisa (2020).

O setor de café beneficiado não se destacou na geração de empregos. Para cada milhão de reais de aumento em sua demanda final, o setor gerou 16 novos empregos diretos e indiretos, se posicionando em $23^{\circ}$ lugar entre os setores, conforme Tabela 9.

Tabela 9 - Multiplicador de Emprego.

\begin{tabular}{|c|c|c|}
\hline Setor & Valor & Ordem \\
\hline Serviços domésticos & 90,7335 & 1 \\
\hline Pecuária & 47,5211 & 2 \\
\hline Confecção de vestuário e acessórios & 34,3949 & 3 \\
\hline Organizações associativas e outros serviços pessoais & 33,9623 & 4 \\
\hline Atividades artísticas, criativas e de espetáculos & 31,5784 & 5 \\
\hline Alimentação & 27,2466 & 6 \\
\hline Produção florestal & 26,7095 & 7 \\
\hline Abate e produtos de carne & 24,9568 & 8 \\
\hline Alojamento & 23,0055 & 9 \\
\hline Educação privada & 22,4401 & 10 \\
\hline Café beneficiado & 16,5676 & 23 \\
\hline
\end{tabular}

Fonte: Elaborado a partir de dados da pesquisa (2020).

O setor de café beneficiado ficou apenas na $52^{a}$ posição na geração de renda do trabalho, dentre os 69 setores da economia. Assim, cada aumento de mil reais na demanda final desse setor gera renda direta e indireta em todos os setores da economia para atender a essa mudança na ordem de $\mathrm{R} \$ 345$.

Tabela 10 - Multiplicador de Renda.

\begin{tabular}{lccc} 
& Setor & Valor & Ordem \\
Serviços domésticos & & 1,0000 & 1 \\
Educação pública & & 0,8663 & 2 \\
\hline
\end{tabular}

Fonte: Elaborado a partir de dados da pesquisa (2020). 
Tabela 10 - Continuação...

\begin{tabular}{llc}
\multicolumn{1}{c}{ Setor } & Valor & Ordem \\
Atividades de vigilância, segurança e investigação & 0,7860 & 3 \\
Saúde pública & 0,7555 & 4 \\
Administração pública, defesa e seguridade social & 0,7197 & 5 \\
Educação privada & 0,6991 & 6 \\
Alojamento & 0,5716 & 7 \\
Outras atividades administrativas & 0,5608 & 8 \\
Edição e edição integrada à impressão & 0,5516 & 9 \\
Armazenagem e atividades auxiliares dos transportes & 0,5053 & 10 \\
Café beneficiado & $\mathbf{0 , 3 4 5 7 5}$ & $\mathbf{5 2}$ \\
\hline
\end{tabular}

Fonte: Elaborado a partir de dados da pesquisa (2020).

Por fim, para cada mil reais na demanda final do setor de café beneficiado, são gerados $\mathrm{R} \$ 91$ de impostos líquidos diretos e indiretos em toda a economia nacional.

Tabela 11 - Multiplicador de Imposto.

\begin{tabular}{|c|c|c|}
\hline Setor & Valor & Ordem \\
\hline Refino de petróleo e coquerias & 0,2141 & 1 \\
\hline Transporte aéreo & 0,1666 & 2 \\
\hline Energia elétrica, gás natural & 0,1329 & 3 \\
\hline Fabricação de bebidas & 0,1224 & 4 \\
\hline Fabricação de produtos de minerais não-metálicos & 0,1125 & 5 \\
\hline Fabricação de automóveis, caminhões e ônibus, exceto peças & 0,1110 & 6 \\
\hline Fabricação de produtos de limpeza e cosméticos & 0,1086 & 7 \\
\hline Abate e produtos de carne & 0,1056 & 8 \\
\hline Fabricação de calçados e couro & 0,1056 & 9 \\
\hline Metalurgia de metais não-ferrosos & 0,1047 & 10 \\
\hline Café beneficiado & 0,09126 & 27 \\
\hline
\end{tabular}

Fonte: Elaborado a partir de dados da pesquisa (2020).

Analisando os multiplicadores, observa-se que o setor de café beneficiado figurou nas primeiras posições no ranking dos setores da economia nacional somente no que se refere à produção.

\subsection{ANÁLISE DO AUMENTO DAS EXPORTAÇÕES DO SETOR DE CAFÉ BENEFICIADO}

Nessa seção, busca-se analisar os impactos do acordo comercial entre a UE e o Mercosul para a economia brasileira, com foco no setor de café beneficiado. Conforme apresentado em seções anteriores, o setor de café terá as tarifas de exportação eliminadas em quatro anos após a implantação do acordo. Conforme o diretor da associação que representa as indústrias de café solúvel no Brasil, estima-se que o impacto nas exportações do setor será de $33 \%$ em cinco anos. Dessa forma, foi dado um choque na demanda final do setor de café beneficiado supondo crescimento de 33\% ( $R \$ 71,06$ milhões) nas exportações desse produto.

$\mathrm{Na}$ Tabela 12, estão apresentados os valores da produção gerada pelo aumento das exportações do setor de café beneficiado. O valor de produção gerado direta e indiretamente a partir do choque na demanda final foi de mais de $\mathrm{R} \$ 158,3$ milhões. A maior parte desse valor de produção seria gerada no próprio setor, no valor de aproximadamente $R \$ 71,1$ milhões. 
Em seguida, tem-se que os setores de agricultura, inclusive o apoio à agricultura e a pós-colheita, comércio por atacado e varejo, transporte terrestre e outros produtos alimentares seriam os setores mais encadeados em suas produções pelo aumento das exportações de café beneficiado.

Tabela 12 - Produção gerada pelo aumento das exportações do setor de café beneficiado.

\begin{tabular}{|c|c|c|}
\hline Setor & Valor (em milhões de R\$) & Ordem \\
\hline Café beneficiado & 71,1091 & 1 \\
\hline Agricultura & 18,2859 & 2 \\
\hline Comércio por atacado e a varejo & 11,1823 & 3 \\
\hline Transporte terrestre & 6,7662 & 4 \\
\hline Outros produtos alimentares & 6,6343 & 5 \\
\hline Refino de petróleo e coquerias & 4,4073 & 6 \\
\hline Intermediação financeira & 3,7642 & 7 \\
\hline Fabricação de químicos & 3,5768 & 8 \\
\hline Atividades jurídicas, contábeis, consultoria & 3,1999 & 9 \\
\hline Energia elétrica, gás natural & 2,7914 & 10 \\
\hline Subtotal & 131,7174 & - \\
\hline Demais Setores & 26,5485 & - \\
\hline Total & 158,2659 & - \\
\hline
\end{tabular}

Fonte: Elaborado a partir de dados da pesquisa (2020).

A Tabela 13 mostra o número de empregos que seriam gerados a partir do choque na demanda final. Percebe-se que o aumento de 33\% nas exportações é capaz de criar cerca de 1,2 mil empregos direta e indiretamente na economia nacional. Desse total, 341 seriam criados no próprio setor de café beneficiado. No entanto, outros setores seriam impactados pelo choque, com destaque para a agricultura, inclusive o apoio à agricultura e a pós-colheita, comércio por atacado e varejo, transporte terrestre, pecuária e outros produtos alimentares.

Tabela 13 - Empregos gerados pelo aumento das exportações do setor de café beneficiado.

\begin{tabular}{lcc}
\multicolumn{1}{c}{ Setor } & Valor & Ordem \\
Café beneficiado & $\mathbf{3 4 1}$ & $\mathbf{1}$ \\
Agricultura & 322 & 2 \\
Comércio por atacado e a varejo & 170 & 3 \\
Transporte terrestre & 74 & 5 \\
Pecuária & 55 & 5 \\
Outros produtos alimentares & 29 & 7 \\
Atividades jurídicas, contábeis, consultoria & 28 & $\mathbf{6}$ \\
Outras atividades administrativas & 23 & 9 \\
Armazenagem e atividades auxiliares dos transportes & 10 & 10 \\
Fabricação de produtos de borracha e plástico & 10 & $\mathbf{1 0 6 1}$ \\
Subtotal & 117 \\
Demais Setores & $\mathbf{1 . 0 6}$ \\
Total & $\mathbf{1 . 1 7 7}$ \\
\hline
\end{tabular}

Fonte: Elaborado a partir de dados da pesquisa (2020).

É possível analisar ainda a renda do trabalho que seria gerada na economia nacional a partir do crescimento das exportações (Tabela 14). Observa-se a geração de aproximadamente $\mathrm{R} \$ 24,6$ milhões em renda do trabalho, sendo cerca de $R \$ 8,7$ milhões criados no setor de café beneficiado. Em seguida, tem-se que os setores de comércio por atacado e varejo, agricultura, 
inclusive o apoio à agricultura e pós-colheita, transporte terrestre e intermediação financeira seriam os setores que mais gerariam renda do trabalho a partir do choque na demanda final.

Tabela 14 - Renda do trabalho gerada pelo aumento das exportações do setor de café beneficiado.

\begin{tabular}{|c|c|c|}
\hline Setor & Valor (em milhões de $\mathbf{R} \$$ ) & Ordem \\
\hline Café beneficiado & 8,7282 & 1 \\
\hline Comércio por atacado e a varejo & 3,5823 & 2 \\
\hline Agricultura & 1,6682 & 3 \\
\hline Transporte terrestre & 1,6119 & 4 \\
\hline Intermediação financeira & 0,9466 & 5 \\
\hline Atividades jurídicas, contábeis, consultoria & 0,8783 & 6 \\
\hline Outros produtos alimentares & 0,7854 & 7 \\
\hline Outras atividades administrativas & 0,6333 & 8 \\
\hline Armazenagem e atividades auxiliares dos transportes & 0,5791 & 9 \\
\hline Fabricação de produtos de borracha e plástico & 0,4776 & 10 \\
\hline Subtotal & 19,8909 & - \\
\hline Demais Setores & 4,6781 & - \\
\hline Total & 24,5690 & - \\
\hline
\end{tabular}

Fonte: Elaborado a partir de dados da pesquisa (2020).

Por fim, observa-se que a expansão das exportações do setor de café beneficiado irá gerar direta e indiretamente cerca de $\mathrm{R} \$ 6,5$ milhões em impostos na economia nacional (Tabela 15). Somente no setor de café beneficiado seriam criados aproximadamente $R \$ 2,8$ milhões em impostos. Dentre os demais setores, destacam-se: agricultura, inclusive o apoio à agricultura e a pós-colheita, refino de petróleo e coquerias, comércio por atacado e varejo e transporte terrestre como maiores geradores de impostos a partir do choque.

Tabela 15 - Impostos gerados pelo aumento das exportações do setor de café beneficiado.

\begin{tabular}{|c|c|c|}
\hline Setor & Valor (em milhões de $\mathbf{R} \$$ ) & Ordem \\
\hline Café beneficiado & 2,8180 & 1 \\
\hline Agricultura & 0,6229 & 2 \\
\hline Refino de petróleo e coquerias & 0,5736 & 3 \\
\hline Comércio por atacado e a varejo & 0,2900 & 4 \\
\hline Transporte terrestre & 0,2657 & 5 \\
\hline Outros produtos alimentares & 0,2653 & 6 \\
\hline Energia elétrica, gás natural & 0,2120 & 7 \\
\hline Fabricação de químicos & 0,1924 & 8 \\
\hline Fabricação de produtos de borracha e plástico & 0,1160 & 9 \\
\hline Intermediação financeira & 0,1061 & 10 \\
\hline Subtotal & 5,4620 & - \\
\hline Demais Setores & 1,0227 & - \\
\hline Total & 6,4846 & - \\
\hline
\end{tabular}

Fonte: Elaborado a partir de dados da pesquisa (2020).

Nesta seção, foram analisados os impactos que a exclusão das tarifas de exportação de café torrado e solúvel (beneficiado) para a União Europeia causarão na economia brasileira. Para isso, foi dado um choque na demanda final do setor de café beneficiado supondo crescimento de 33\% (R $\$ 71,06$ milhões) nas exportações desse produto. Os resultados mostram que o acordo proporcionará aumento na produção nacional, principalmente no setor de café beneficiado e 
nos que estão interligados com ele. Além disso, a elevação da produção impactará positivamente o número de empregos, a renda oriunda do trabalho e os impostos diretos e indiretos.

\section{CONCLUSÕES}

Este trabalho teve como objetivo identificar os efeitos diretos e indiretos do aumento das exportações do setor de café beneficiado devido ao acordo comercial entre o Mercosul e a União Europeia. A fim de responder a essa pergunta, o estudo utilizou o ferramental metodológico insumo-produto. Os dados utilizados foram obtidos das Contas Nacionais, Ministério das Relações Exteriores (sobre o acordo comercial) e do Ministério da Economia, Indústria, Comércio Exterior e Serviços (sobre o comércio entre o Brasil e a União Europeia).

Analisando os setores que apresentam mais e menos encadeamento dentro do processo produtivo do setor de café beneficiado, verificaram-se fortes ligações com o setor de agricultura, inclusive o apoio à agricultura e a pós-colheita, com comércio por atacado e a varejo, transporte terrestre, outros produtos alimentares e refino de petróleo e coquerias. De forma contrária, os setores menos encadeados com o setor de café beneficiado são os de serviços domésticos, fabricação de produtos de fumo, saúde pública, saúde privada e fabricação de calçados de couro.

Considerando o crescimento de $33 \%$ nas exportações do café beneficiado após o acordo comercial entre Mercosul e União Europeia, foi dado um choque na demanda final desse setor no montante de $R \$ 71,06$ milhões. Observou-se que o aumento nas exportações proporcionará produção nacional direta e indiretamente de $R \$ 158,3$ milhões, ou seja, a economia nacional encadearia valor de produção em cerca de $223 \%$ desse choque na demanda final. Além disso, serão gerados 1,2 mil novos empregos, $R \$ 24,6$ milhões em renda do trabalho e $R \$ 6,5$ milhões em impostos.

Os setores que foram mais encadeados pelo aumento das exportações de café beneficiado foram agricultura, inclusive o apoio à agricultura e a pós-colheita, comércio por atacado e varejo, transporte terrestre, outros produtos alimentares, pecuária, intermediação financeira e refino de petróleo e coquerias.

Portanto, os resultados encontrados por este trabalho evidenciam a importância do acordo comercial entre a União Europeia e o Mercosul para a economia brasileira. O referido acordo propiciará crescimento na produção nacional e, como consequência disso, o número de empregos, a renda oriunda do trabalho e os impostos diretos e indiretos também aumentarão.

É importante ressaltar que os modelos de insumo-produto possuem algumas limitações e hipóteses. Esses modelos adotam retornos constantes de escala, assumem implicitamente oferta perfeitamente elástica, preços constantes, inexistência de ilusão entre os agentes econômicos e admitem que os coeficientes técnicos são invariáveis ao longo do tempo. No entanto, mesmo com as limitações supracitadas, a técnica de insumo-produto é uma ferramenta útil para o planejamento de políticas setoriais e desenvolvimento regional, em virtude de oferecer mecanismos de análise para alocação eficiente dos recursos econômicos. Além disso, torna-se importante também por fornecer uma grandeza do montante de emprego, renda, impostos e valor adicionado que serão criados por um determinado choque na cadeia produtiva.

Como trabalhos futuros, consideramos importante o seguinte aspecto: a produção de café beneficiado no Brasil não é homogênea entre os estados, portanto seria relevante analisar o impacto do aumento das exportações de café beneficiado para a União Europeia para cada região produtora de café, através da matriz insumo-produto inter-regional. 


\section{REFERÊNCIAS}

Bernal-Meza, R. (2005). América Latina en el Mundo: el pensamiento latinoamericano y la teoría de relaciones internacionales. Nuevo Hacer, Grupo Editor Latinoamericano.

Brasil. Ministério da Economia, Indústria, Comércio Exterior e Serviços. (2020). Sistemas de comércio exterior. Brasília. Recuperado em 10 de fevereiro de 2020, de http://www. siscomex.gov.br/

Bresser-Pereira, L. C., \& Thorstensen, V. H. (1992). Do Mercosul à Integração Americana. Política Externa, 1(3), 122-145.

Chen, W., Wu, S., Lei, Y., \& Li, S. (2018). Virtual water export and import in china's foreign trade: a quantification using input-output tables of China from 2000 to 2012. Resources, Conservation and Recycling, 132, 278-290.

Goodlass, G., Halberg, N., \& Verschuur, G. (2001). Study on input/output accounting systems on EU agricultural holdings. Utrecht: Centre for Agriculture and Environment.

Guilhoto, J. J. (2011). Input-output analysis: theory and foundations (MPRA Paper, No. 32566).

Guilhoto, J. J. M., \& Sesso Filho, U. A. (2005). Estimação da Matriz Insumo-Produto a Partir de Dados Preliminares das Contas Nacionais. Economia Aplicada, 9(2), 277-299.

Guilhoto, J. J. M., \& Sesso Filho, U. A. (2010). Estimação da matriz insumo-produto utilizando dados preliminares das contas nacionais: aplicação e análise de indicadores econômicos para o Brasil em 2005. Economia \& Tecnologia, 6(23), 53-62.

Guimarães, S. P. (2014). Entrevista: acordo vai ser uma desgraça. Recuperado em 1 de dezembro de 2019, de www.cartacapital.com.br/economia/acordo-vai-ser-uma-desgraca-134

Instituto Brasileiro de Geografia e Estatística - IBGE. (2017) Sistema de Contas Nacionais (SCN). Recuperado em 6 de janeiro de 2020, de https://www.ibge.gov.br/estatisticas/economicas/ comercio/9052-sistema-de-contas-nacionais-brasil.html?=\&t=o-que-e

International Trade Centre. (2017). List of exporters for the selected product: total all product. Trade Map. Recuperado em 10 de fevereiro de 2020, de www.trademap.org

Leontief, W. (1951). The structure of the American economy. New York: Oxford University Press.

Mercosul. Secretaria do Mercosul. (2020). Sistema de estatística de comércio exterior do Mercosul. Recuperado em 12 de dezembro de 2020, de https://estadisticas.mercosur.int/?language=pt

Miller, R. E., \& Blair, P. D. (2009). Input-output analysis: foundations and extensions. Cambridge: Cambridge University Press.

Nasser, M. D., Tarsitano, M. A. A., Lacerda, M. D., \& Koga, P. S. L. (2012). Análise econômica da produção de café arábica em São Sebastião do Paraíso, estado de Minas Gerais. Informações Econômicas, 42(2), 5-12.

Nassif, L., Teixeira, L., \& Rocha, F. (2015). Houve redução do impacto da indústria na economia brasileira no período 1996-2009? Uma análise das matrizes insumo-produto. Economia e Sociedade, 24(2), 355-378.

Nonnenberg, M. J. B., \& Ribeiro, F. J. (2019). Análise preliminar do acordo Mercosul-União Europeia (Carta de Conjuntura, No. 44). Brasília: Instituto de Pesquisa Econômica Aplicada.

Núcleo de Economia Regional e Urbana da USP - Nereus. (2021). Sistema de Matrizes de Insumo-Produto, Brasil (2010-2018). Recuperado em 31 de março de 2021, de http://www. usp.br/nereus/?fontes=dados-matrizes 
Ozkan, B., Akcaoz, H., \& Fert, C. (2004). Energy input-output analysis in Turkish agriculture. Renewable Energy, 29(1), 39-51.

Pennaforte, C., Ribeiro, G. S., \& Bones, N. K. (2018). Acordo Mercosul-União Europeia: entre o discurso e a realidade: impactos e perspectivas. Conjuntura Austral, 9(46), 5-21.

Revista Exame. (2019). Acordo UE/Mercosul tem impacto limitado no comércio agrícola. Recuperado em 1 de novembro de 2019, de www.exame.abril.com.br/economia/acordoue-mercosul-tem-impacto-limitado-no-comercio-agricola/

Sakon, F. M., Guilhoto, J. J. M., Bliska, F. M. M., Imori, D., \& Camargo, F. S. (2008). A produção e industrialização do café dos principais produtores brasileiros e a economia nacional: simulações sob um modelo inter-regional de insumo-produto (MPRA Paper, No. 54033).

Santos, V. E., Gomes, M. F. M., Braga, M. J., \& Silveira, S. F. R. (2009). Análise do setor de produção e processamento de café em Minas Gerais: uma abordagem matriz insumo-produto. Revista de Economia e Sociologia Rural, 47(2), 363-388.

Seixas, L. O., Souza, C. C. A., Maciel, L. L., \& Portugal, P. H. S. (2020). Especialização regressiva em minas gerais de 2008 a 2013: a análise da produção de café em grão e torrado e moído a partir das matriz insumo-produto. Revista Economica do Nordeste, 51(1), 73-88.

Shao, L., Guan, D., Wu, Z., Wang, P., \& Chen, G. Q. (2017). Multi-scale input-output analysis of Consumption-based water resources: method and applications. Journal of Cleaner Production, 164, 338-346.

Sugai, Y., Teixeira Filho, A. R., Contini, E. (2004). Impacto de exportação do café na economia do Brasil (Texto para Discussão, No. 20). Brasília: Embrapa Informação Tecnológica.

Takasago, M., Mollo, M. L. R., \& Guilhoto, J. J. M. (2017). O debate desenvolvimentista no Brasil: discutindo resultados da matriz de insumo-produto. Planejamento e Políticas Públicas, 48, 385-409.

Zheng, B., Huang, G., Liu, L., Guan, Y., \& Zhai, M. (2020). Dynamic wastewater-induced research based on input-output analysis for Guangdong Province, China. Environmental Pollution, $256,113502$. 